\title{
Os negros e as diferenças no mercado de trabalho da região metropolitana de São Paulo: considerações sobre o nível de escolaridade dos ocupados ${ }^{1}$
}

* (Fundação Sistema Estadual de Análise de Dados -Seade, São PauloSP, Brasil)
Resumo: A desigualdade racial tem sua origem no funcionamento da economia de plantação do período colonial e ainda pode ser percebida no mercado de trabalho atual. Na Região Metropolitana de São Paulo, as informações da Pesquisa de Emprego e Desemprego (PED) mostram que a taxa de desemprego dos negros, de 19,2\% em 2018, é tradicionalmente mais elevada do que a dos não negros. Sua inserção ocupacional costuma ocorrer em postos com qualificação e rendimentos mais baixos do que os dos não negros. Apesar do importante aumento do nível de escolaridade, a proporção de ocupados negros com nível superior é equivalente a menos da metade da participação dos não negros e os diferenciais por raça/cor dos rendimentos de quem possui esse nível de ensino são os maiores.

Palavras-chave: Desigualdade racial. Mercado de trabalho. Taxa de desemprego. Nível de escolaridade. Ocupação.

\footnotetext{
${ }^{1}$ Este artigo baseia-se em publicações da Fundação Seade sobre o negro no mercado de trabalho, elaboradas pela equipe de análise, da qual faço parte. Agradeço à Neuci Arizono e à Susana M. F. Pereira pelo minucioso trabalho com o processamento e averiguação dos dados, bem como a Alexandre Jorge Loloian e à Paula Montagner por seus comentários sempre bem-vindos.
} 
INTRODUÇÃO

A desigualdade racial ainda precisa ser muito debatida. 0 mito da democracia racial impediu - ou vem impedindo - o amplo reconhecimento das diferenças entre negros e não negros no Brasil, o que faz dele um tema relativamente recente, do ponto de vista histórico, para boa parte da população.

Apenas com a organização dos movimentos negros no início do século $X X$, a imprensa negra, o teatro experimental do negro e a formação de uma consciência social negra foi possível confrontar a falsa ideia de democracia racial, ainda que com alcance restrito a certos nichos populacionais. Além da própria militância e intelectualidade negra, merece destaque a contribuição de estudos importantes, como os de Florestan Fernandes, por apresentarem a fundamentação teórica para a compreensão das diferenças raciais. A compreensão dessa realidade envolve reconhecer a existência do preconceito de cor, da discriminação de raça, das diferenças de acesso à educação e diferenças de condições de vida - questões que têm na escravidão a mesma origem histórica, como bem mostra Florestan Fernandes.

A desigualdade racial está estreitamente ligada à função da escravidão no Brasil. Não se trata apenas de ter sido o país a receber o maior número de escravos nos quase quatro séculos de comercialização humana entre os continentes africano e americano (estima-se que o Brasil tenha sido o destino de $47 \%$ dos cerca de 12,5 milhões de africanos deportados para a América) ${ }^{2}$, ou o último a declarar a abolição, mas trata-se, principalmente, de entender o papel da escravidão na economia colonial e reconhecer seus efeitos maléficos e duradouros na sociedade.

Alguns desses efeitos serão apresentados no presente artigo por meio de informações estatísticas do maior mercado de trabalho do país - e com o maior número absoluto de negros -, o da Região Metropolitana de São Paulo, utilizando-se indicadores da Pesquisa de Emprego e Desemprego (PED), realizada pela Fundação Seade, em parceria com o Departamento Intersindical de Estatística e Estudos Socioeconômicos (Dieese).

Dos 12.521.337 escravos que deixaram a costa africana entre 1501 e 1875, 1.818.680 morreram na travessia. Voyages: The Transatlantic Slave Trade Database. Atlanta/EUA: Emory University; Kingston upon Hull/Inglaterra: University of Hull. Disponível em: www. slavevoyages.org. Acesso em: 21 nov. 2018. 
Tomadas as palavras de Fernandes (2010), a sociedade escravocrata no Brasil foi uma tentativa de reprodução da ordem social de Portugal - esta, organizada na época dos grandes descobrimentos, como um complexo Estado patrimonial. Nesse sentido, reproduziu-se aqui a sua estrutura de poder e a sua burocracia, tendo na escravidão seu maior diferencial e principal eixo de funcionamento, com o qual se promoveu o empobrecimento e o enrijecimento dessa ordem societária estamental.

As estruturas de poder eram demarcadas pelas concessões de sesmarias, com as quais foi mantida a estratificação que servia de base social à existência e ao fortalecimento do Estado patrimonial na colônia de exploração. Essa estrutura - ou a lógica da política para manter essa estrutura - foi responsável pela criação do latifúndio e pela exclusão da população livre da posse da terra, do controle do poder local e do direito de obter qualquer relação direta com o Estado. A terra ainda não era propriamente uma riqueza, somente mais tarde adquiriria esse significado, mas estava na base material da transferência e da perpetuação de uma estrutura de privilégios e da própria dominação patrimonialista.

O escravo era a principal mercadoria de uma ampla rede de negócios (da captura e do tráfico ao mercado de escravos e à forma de trabalho), constituindo-se como o alicerce da acumulação do capital mercantil. Nas várias formas de relação da sociedade escravista havia várias formas de dominação e de espoliação - dentro da colônia e fora dela, pela Coroa - e, em todos os níveis, a escravidão era a base e a condição para a acumulação e a concentração do capital mercantil.

\footnotetext{
[...] a escravidão mercantil só poderia implantar-se e desenvolver-se em uma ordem societária dessa natureza, na qual se definia a figura legal do escravo, simultaneamente, como um "inimigo doméstico" e um "inimigo público". O ponto de apoio estrutural e dinâmico desse tirânico estilo de acomodação interétnica e inter-racial nascia de uma confluência e da conjugação de formas de repressão, de controle armado e de despotismo generalizado (forjadas e mantidas pela superposição de estamentos e castas) [...] (FERNANDES, 2010, p. 73).
}

A despeito das tensões e dos conflitos, a Coroa dependia do arranjo das correlações com os colonos para a construção e o progresso da colônia de exploração. Além de fatores internos, no início do século XIX medidas externas de contenção ou proibição do tráfico negreiro, alinhadas ao capitalismo, chegariam ao Brasil de forma muito lenta até serem transformadas em leis. "A 
crise da ordem escravocrata e senhorial surgiu [...] por causa do problema da renovação da escravaria e da reprodução do trabalho escravo [...], agravada pelas pressões dinâmicas decorrentes da expansão do setor capitalista novo" (FERNANDES, 2010, p. 83).

A escravidão estava fadada a desaparecer, mas, para o senhor, as demais condições de sua riqueza e poder se manteriam: monopólio da terra, forte predomínio no controle das estruturas de poder político, participação no crescimento econômico urbano-comercial, despotismo social, etc. A vítima da crise final dessa ordem - e ainda hoje - foi o negro como categoria social. Liberto, não tinha trabalho, ou apenas em condições muito ruins, impossibilitado de competir com o trabalhador branco. Muitos passaram a viver da economia de subsistência e muitos outros foram vencidos pela situação de extrema pobreza em que foram deixados.

Os senhores, já na fase de formação do capitalismo competitivo dependente, conseguiram prolongar ao máximo a duração da escravidão, para terem mais tempo de substituir o escravo pelo trabalhador livre e, principalmente, para explorar mais intensamente o trabalho escravo. Essa antiga forma de produção coexistiu durante muito tempo com o capitalismo que surgia.

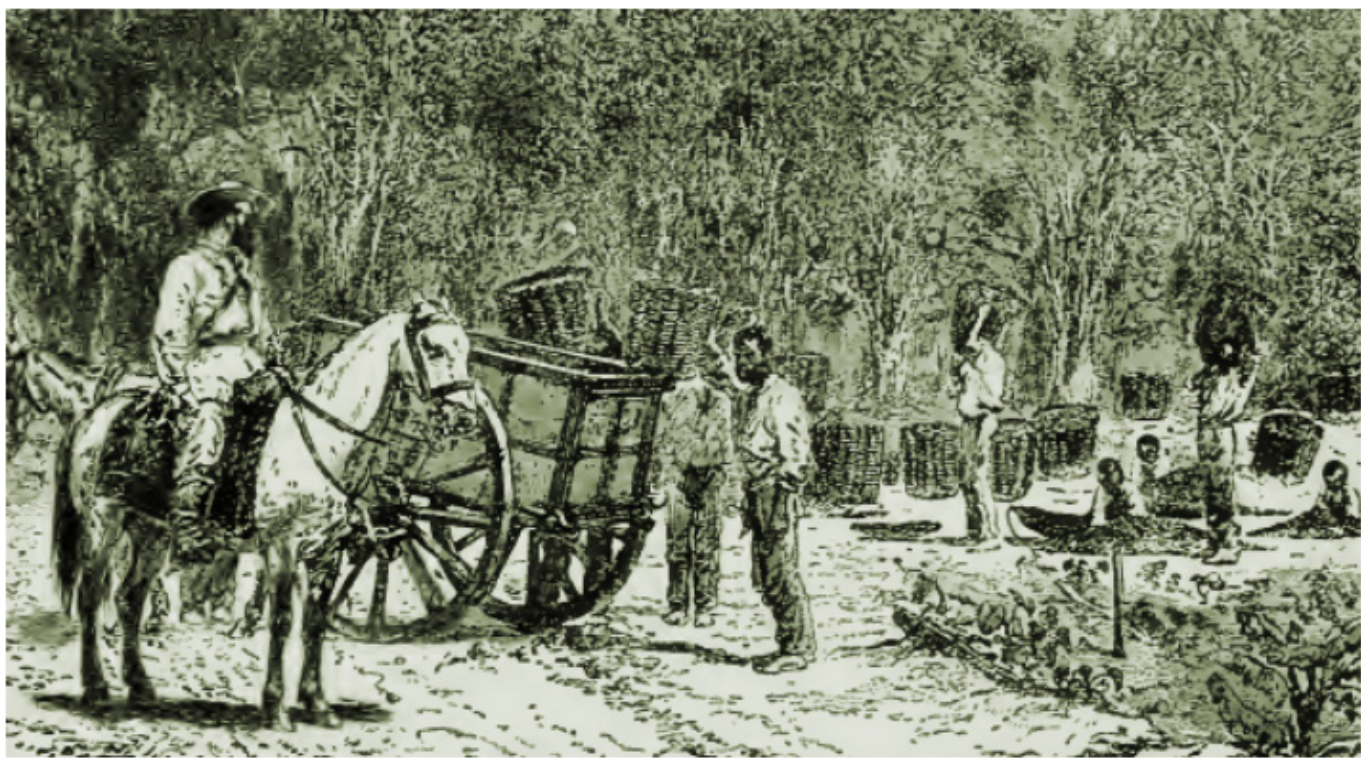

Fonte: Sellin (1885, p. 177).

O fim do modo de produção escravista deve-se, também, aos imigrantes, que o confrontaram e forçaram sua gradual eliminação, não por solidariedade ao ex-escravo, mas porque o modo escravista de produção rebaixava o valor do 
trabalho e provocava a persistência de padrões de dominação inaceitáveis para o trabalhador livre, impedindo o aparecimento de um verdadeiro mercado de trabalho.

Naquele contexto, a campanha abolicionista foi apenas mais uma forma de pressão para o fim da escravidão.

A revolução social vinculada à desagregação da produção escravista e da ordem social correspondente, desencadeadora da abolição e da proclamação da república, não se fazia para toda a sociedade brasileira. [...] Tratava-se de uma revolução das elites, pelas elites e

para as elites (FERNANDES, 2017, p. 30).

Diante da evasão das obrigações e responsabilidades de uma classe social dominante, era necessário o mito da democracia racial, mantendo-se intacta, assim, uma ordem social arcaica. Sua função era aprisionar o negro em um pensamento predominante que o levasse à negação de si próprio. Para os movimentos negros, a revolução da qual o escravo foi o motivo não se concluiu, porque ele não se converteu em seu agente. Daí a reivindicação da Segunda Abolição contida no Protesto Negro, na década de 1930.

Para os negros, o trabalho livre não significou sua libertação, pois, ao não contarem com um projeto de transição, foram colocados em uma competição desigual com os imigrantes. Na República, o negro não obteve a condição de cidadão. Muitos homens, sem ter como trabalhar, permaneceram em casa, dependentes das mulheres da família, que conseguiam trabalho no âmbito doméstico. Outros foram levados a realizar os piores trabalhos com baixíssima remuneração, em uma espécie de repetição do que era ser escravo.

Durante a descolonização, as antigas estruturas raciais não foram enfrentadas pela República ou pelos abolicionistas. Os privilégios construídos permaneceram intocados. "A descolonização confundiu-se com os interesses do senhor", enquanto "o escravo, o liberto e o branco pobre permaneceram encadeados à colonização, às suas necessidades imperiosas, que os despojavam de sua condição humana" (FERNANDES, 2017, p. 45). Mesmo ao desaparecer, o trabalho escravo deixou atrás de si resquícios das estruturas raciais e formas de trabalho semilivre ou análogas ao trabalho escravo, de dominação e de exploração, que persistem até hoje. 
Foi no início dos mais de três séculos de escravidão no país que se estruturou o funcionamento da economia e da sociedade colonial, mantendo-se, em alguns aspectos, na economia e na sociedade de hoje. Um dos aspectos que perduram é o mito da democracia racial, que serviu para preservar as imensas desigualdades existentes e que são, em certa medida, perceptíveis nos indicadores de mercado de trabalho.

A população negra ${ }^{3}$ está entre os segmentos com maior dificuldade de inserção no mercado de trabalho ${ }^{4}$. Essa situação é expressa por suas altas taxas de desemprego, em comparação às dos não negros, fato que não se alterou ao longo do tempo, apenas a distância entre ambas, que costuma diminuir nos períodos de maior aquecimento da atividade econômica e aumentar nos períodos de recessão, conforme observado na série da Pesquisa de Emprego e Desemprego (PED) iniciada em 1985, na Região Metropolitana de São Paulo (Gráfico 1).

Em 2018, a taxa de desemprego dos negros, na Região Metropolitana de São Paulo, chegou a $19,2 \%$ e a dos não negros, a $14,7 \%$ da população economicamente ativa (PEA).

Os efeitos do desempenho da economia sobre o mercado de trabalho não são imediatos, tanto que, em 2017, a taxa de desemprego continuou crescendo, ainda que em menor ritmo, apesar do fim da crise econômica. Apenas em $2018^{5}$ a taxa de desemprego de negros e não negros voltou a diminuir, apresentando diferença de 4,5 pontos percentuais entre os dois segmentos. Para comparação, essa diferença era de 1,9 ponto percentual em $2014^{6}$, início da crise econômica, mas que repercutiu no mercado de trabalho no ano seguinte.

Neste estudo, o grupo denominado negros refere-se às populações preta e parda e o grupo de não negros, às populações branca e amarela.

4 Entre os segmentos populacionais com taxas de desemprego mais altas, destacam-se, além dos negros, os jovens e as mulheres, tendo-se, assim, as jovens negras como o segmento com a maior taxa de desemprego.

A taxa preliminar de crescimento do Produto Interno Bruto - PIB, na Região Metropolitana de São Paulo, foi calculada em 1,4\% para 2018. Fundação Seade.

$6 \quad \mathrm{Na}$ Região Metropolitana de São Paulo, o Produto Interno Bruto - PIB apresentou as seguintes variações anuais: - $0,8 \%$ em 2014, -4,9\% em 2015, -3,9\% em 2016 e 1,2\% em 2017. Fundação Seade. Disponível em: 〈http://www.seade.gov.br/produtos/pib-anual/〉, PIB Regional, acesso em 26/06/2019. 
Gráfico 1 - Taxas de desemprego, por raça/cor.

Região Metropolitana de São Paulo - 1985-2018

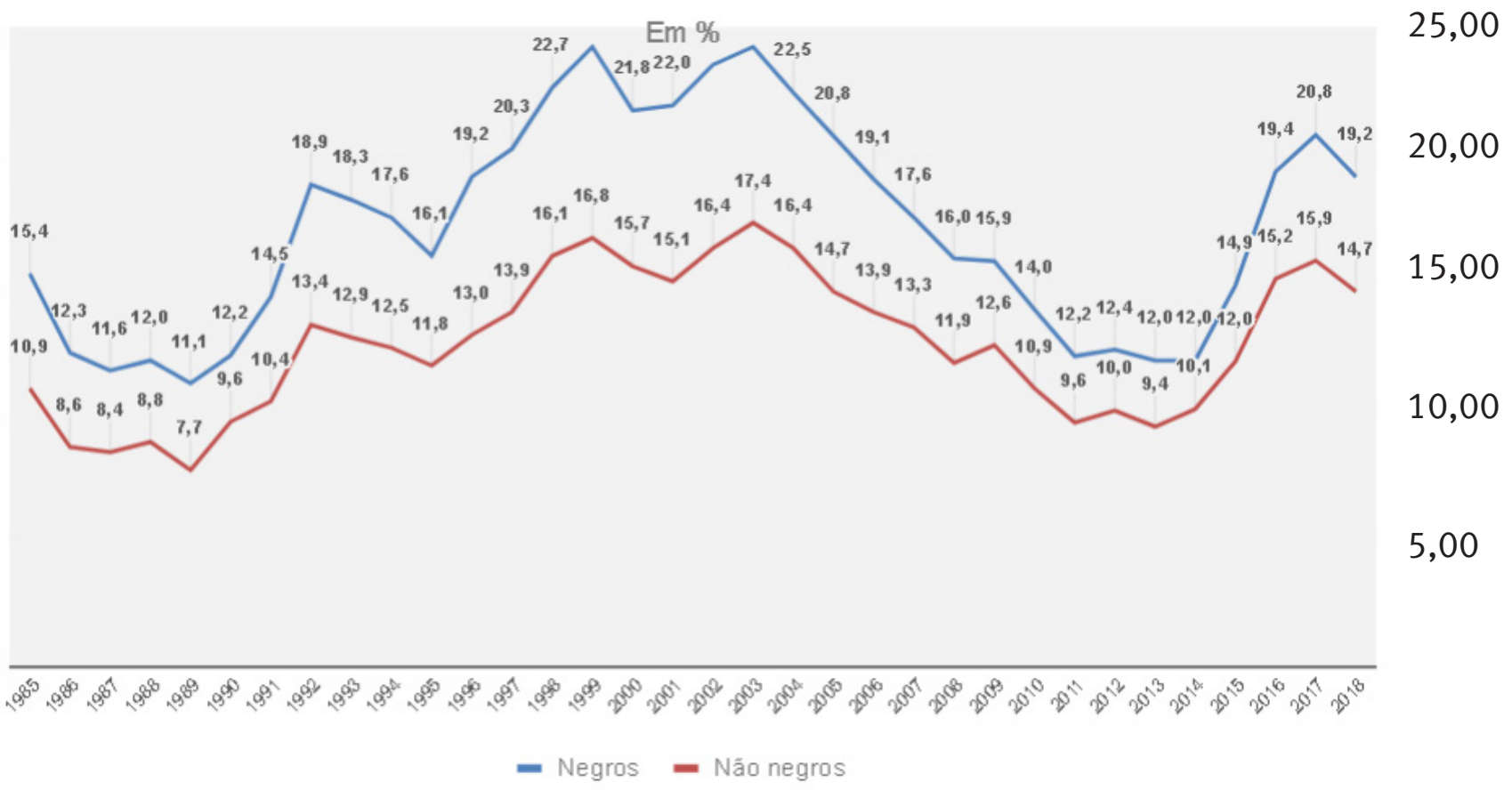

Fonte: Secretaria de Planejamento e Gestão. Convênio Seade-Dieese e Ministério do Trabalho/FAT.

Pesquisa de Emprego e Desemprego (PED).

Em 2018, os negros representavam 42,4\% da população economicamente ativa (PEA) ${ }^{7}$, na Região Metropolitana de São Paulo, e sua proporção no total de ocupados era de 41,1\%, principalmente em postos com menor exigência de qualificação e menor remuneração.

Por posição na ocupação, a participação de negros e não negros, em 2018, era praticamente igual no assalariamento com carteira de trabalho assinada do setor privado (53,3\% e 53,4\%, respectivamente) e no sem carteira assinada (8,0\% e 7,8\%), mas era maior em outras ocupações em que há menor proteção de direitos trabalhistas e previdenciários, como o trabalho autônomo (18,9\% e 17,3\%) e, principalmente, o doméstico (9,5\% e 5,2\%) (Gráfico 2).

Quando se trata de posições mais valorizadas pela qualificação exigida e/ou melhor remuneração, a participação de negros era menor, caso do assalariamento no setor público (6,1\% negros e 8,0\% não negros) e do agregado demais posições ocupacionais, que incluem profissionais universitários autônomos, empregadores, donos de negócio familiar, etc.

População economicamente ativa (PEA) é a parcela da PIA que está ocupada ou desempregada. População em idade ativa (PIA) é a parcela da população com 10 anos de idade ou mais. 
(4,3\% e $8,3 \%$, respectivamente). Esses diferenciais podem ser associados ao nível de escolaridade mais baixo da população negra, em relação à não negra, ou ao baixo acesso a bens e dinheiro para investir no próprio negócio, condições históricas que pouco se alteraram ao longo do tempo.

Gráfico 2 - Distribuição dos ocupados, por raça/cor, segundo posição na ocupação.

Região Metropolitana de São Paulo - 2018

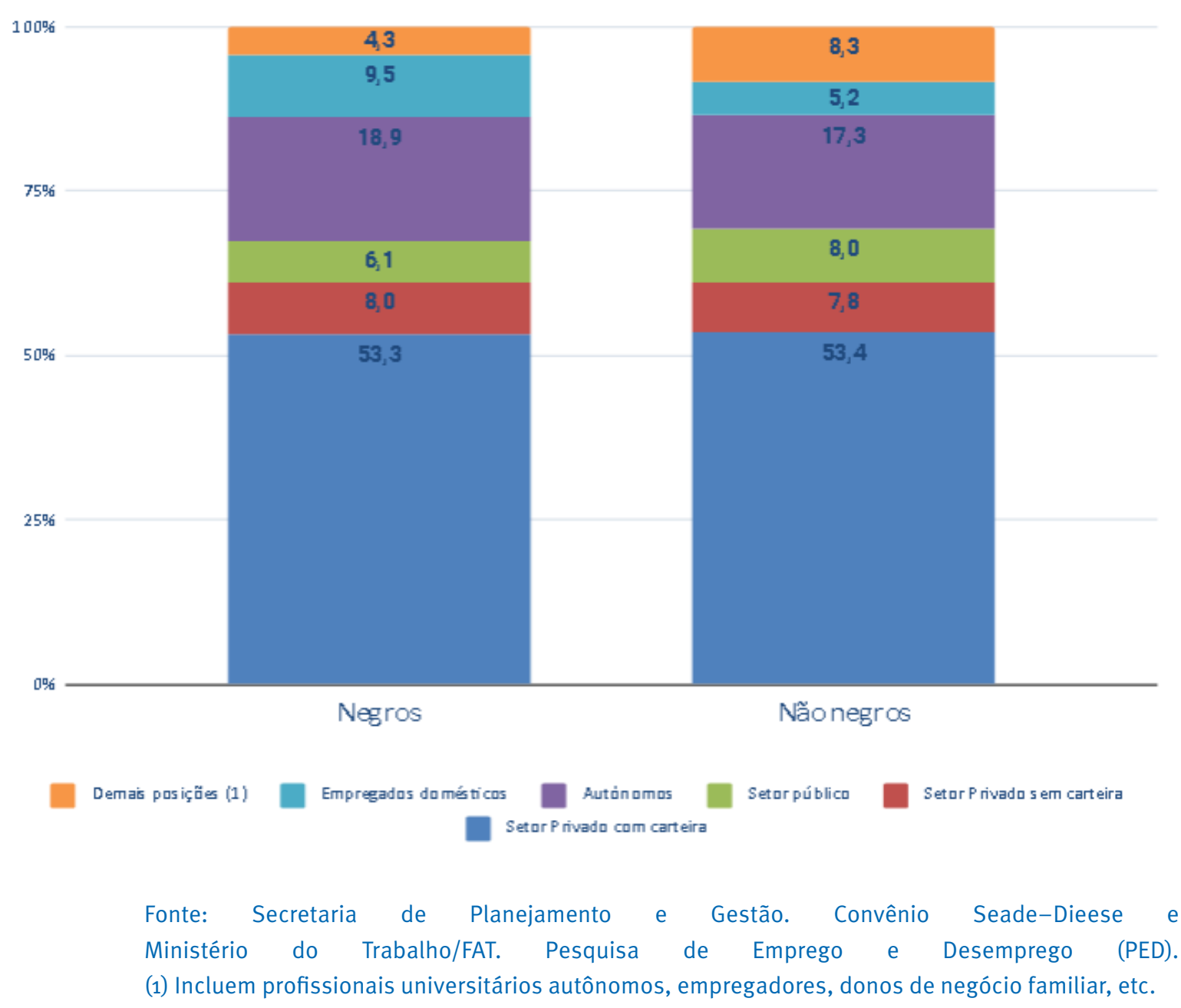

Em relação aos principais setores de atividade econômica, a área de Serviços se destaca por ocupar mais da metade dos trabalhadores. Em 2018, estavam nesse setor $58,9 \%$ do total de negros ocupados e $60,3 \%$ de não negros (Gráfico 3). Há dois segmentos de atividade em Serviços com maior número de ocupados: o primeiro reúne administração pública, defesa e seguridade social, educação, saúde humana e serviços sociais; e o segundo, alojamento e alimentação, outras atividades de serviços, artes, cultura, esporte e recreação. Além desses, distinguem-se, entre os negros, os serviços domésticos e, entre os não negros, o ramo da informação e comunicação, atividades financeiras, 
de seguros e serviços relacionados, atividades profissionais, científicas e técnicas.

Dentre outras diferenças de inserção ocupacional, pode-se destacar a maior participação dos negros, em relação aos não negros, na Construção $(8,2 \%$ do seu total ocupado, contra $5,1 \%$ dos não negros) e a menor representatividade na Indústria (14,3\% e 15,3\%, respectivamente) e no Comércio (17,4\% e 18,3\%).

Gráfico 3 - Distribuição dos ocupados(1), por setor de atividade econômica,

segundo raça/cor. Região Metropolitana de São Paulo - 2018

$\mathrm{Em} \%$

80,0

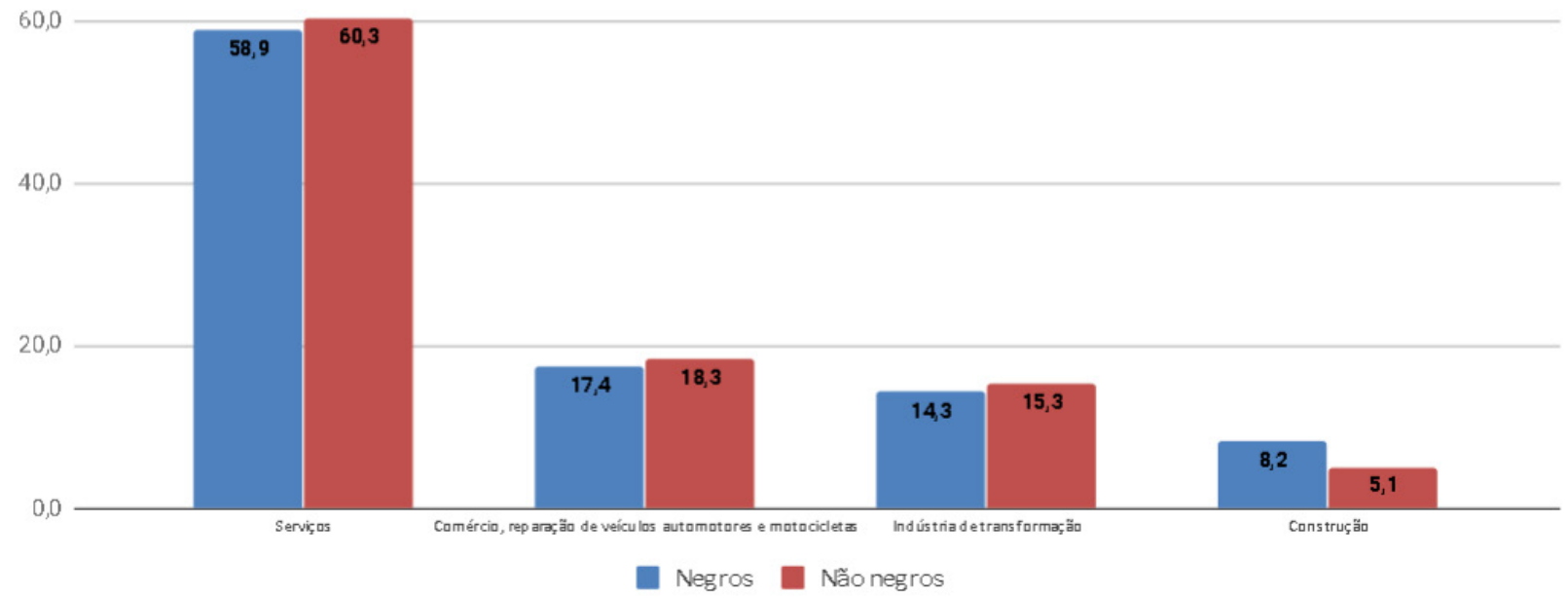

Fonte: Secretaria de Planejamento e Gestão. Convênio Seade-Dieese e Ministério do Trabalho/FAT. Pesquisa de Emprego e Desemprego (PED).

Incluem os assalariados que não sabem a que setor pertencem.

Essas proporções, bem como as encontradas por posição na ocupação, são importantes para ajudar a entender as discrepâncias nos rendimentos entre os dois grupos.

O rendimento do trabalho dos negros correspondia, em média, a $R \$ 1.699$, em 2018 , valor $31 \%$ menor do que o dos não negros ( $R$ \$ 2.448).

A diferença entre os rendimentos médios (Gráfico 4) incide de maneira parecida nas posições ocupacionais (por volta de $29 \%$ menor para os negros), exceto no trabalho autônomo, em que a diferença é um pouco menor ( $24 \%$ ), e no 
emprego doméstico, em que o rendimento dos negros ( $R$ \$ 1.330) é bastante próximo (3\% maior) ao dos não negros (R\$1.285).

Gráfico 4 - Rendimentos médios reais(1) dos ocupados(2), por posição na ocupação, segundo raça/cor. Região Metropolitana de São Paulo - 2018

\section{Em reais}

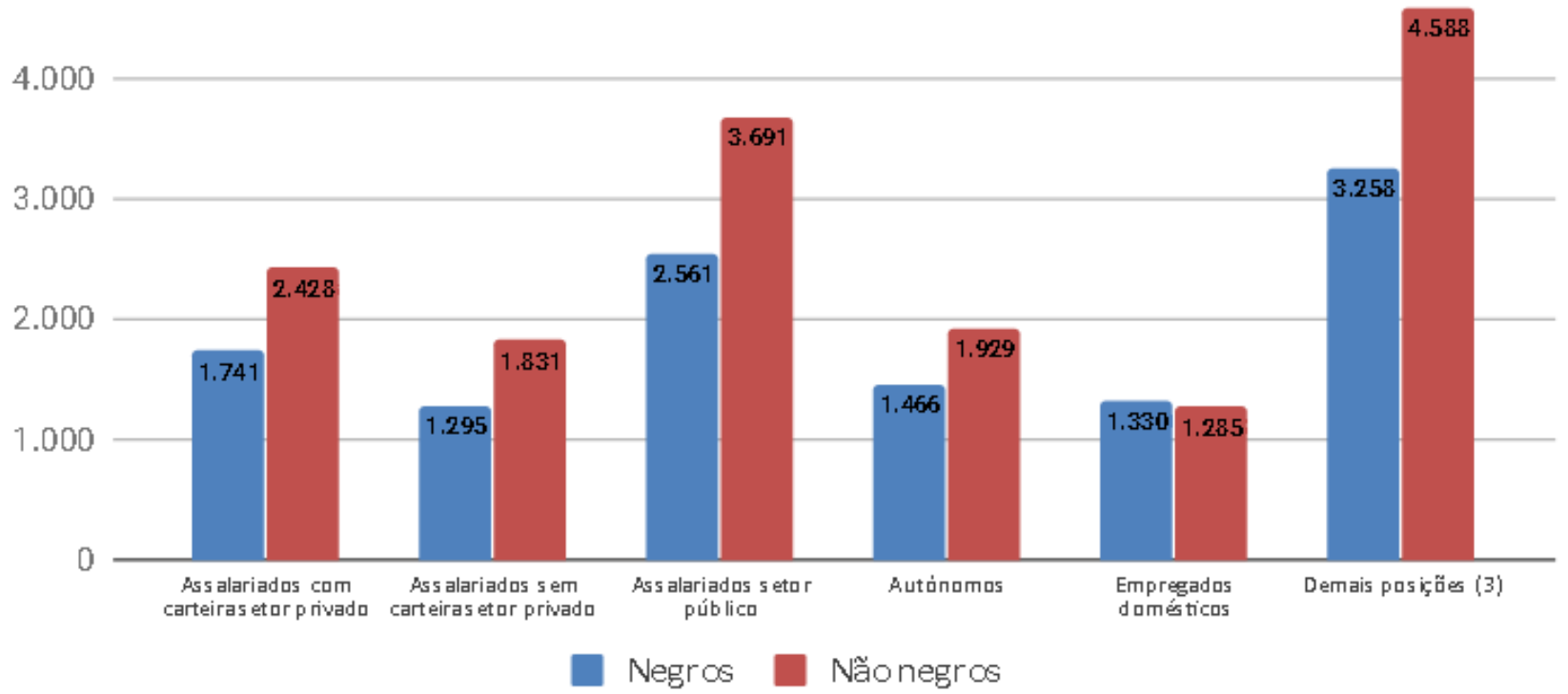

Fonte: Secretaria de Planejamento e Gestão. Convênio Seade-Dieese e Ministério do Trabalho/FAT. Pesquisa de Emprego e Desemprego (PED). 1. Inflator utilizado: ICV do Dieese. Em reais de novembro de 2018. 2. Exceto os assalariados e os empregados domésticos mensalistas que não tiveram remuneração no mês, os trabalhadores familiares sem remuneração salarial e os empregados que receberam exclusivamente em espécie ou benefício. 3. Incluem profissionais universitários autônomos, empregadores, donos de negócio familiar, etc. 0 valor atribuído aos negros apresenta erro amostral acima do usual.

No que se refere aos setores de atividade (Gráfico 5), há maior distância entre os rendimentos pagos nos Serviços (33\%) e na Indústria (28\%) e menor diferença entre os rendimentos médios recebidos na Construção (23\%) e no Comércio (23\%). 
Gráfico 5 - Rendimentos médios reais(1) dos ocupados(2), por setor de atividade econômica, segundo raça/cor. Região Metropolitana de São Paulo - 2018

\section{Em reais}

3.000

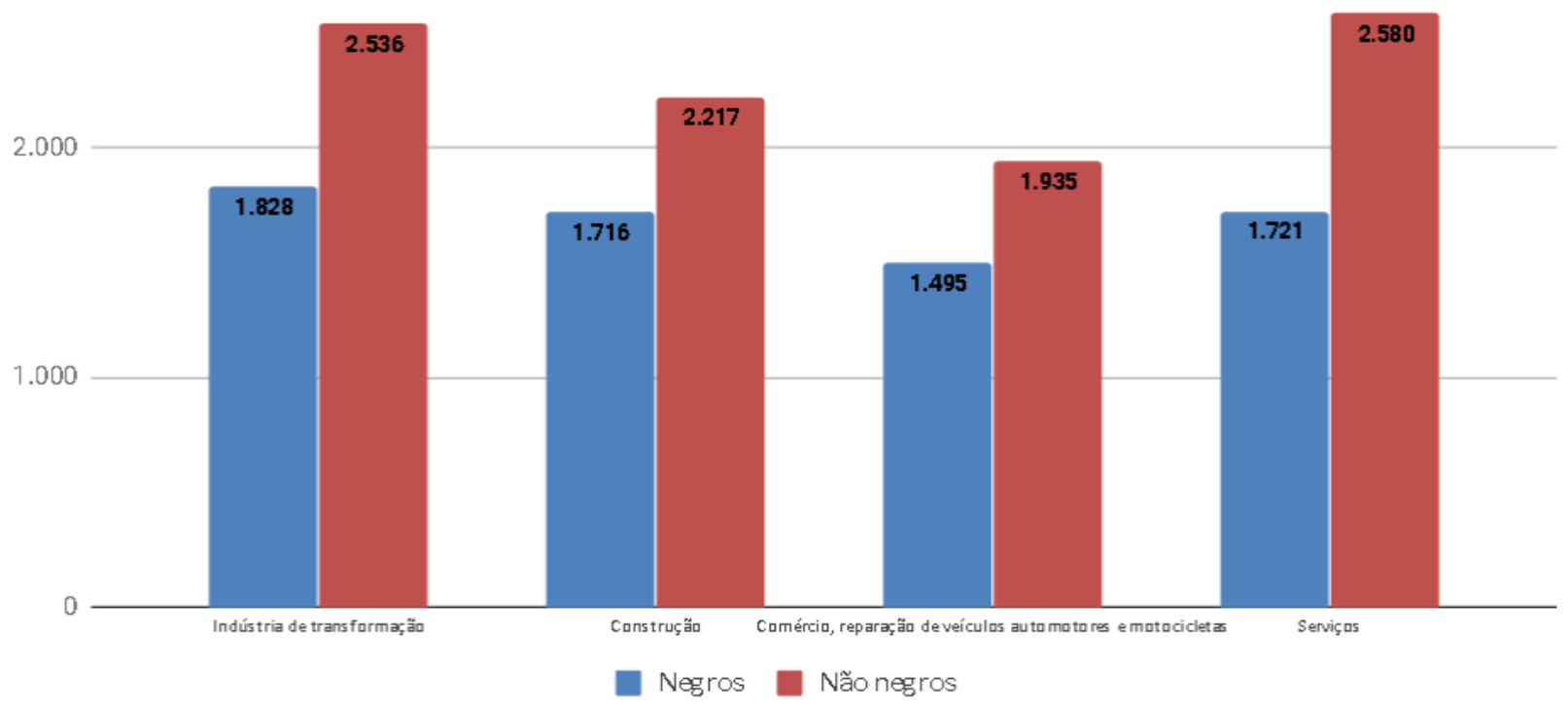

Fonte: Secretaria de Planejamento e Gestão. Convênio Seade-Dieese e Ministério do Trabalho/FAT. Pesquisa de Emprego e Desemprego (PED). 1. Inflator utilizado: ICV do Dieese. Em reais de novembro de 2018. 2. Incluem os assalariados que não sabem a que setor pertencem.

Os rendimentos mais baixos obtidos, em média, pelos negros são reflexo, principalmente, da sua inserção ocupacional, na medida em que eles estão mais presentes - na comparação com os não negros - nos segmentos com essa característica (Construção e alguns ramos de Serviços, inclusive o doméstico) e menos presentes naqueles que costumam registrar remuneração mais alta (Indústria e outros ramos de Serviços, inclusive o de informação e comunicação, atividades financeiras, de seguros e serviços relacionados, atividades profissionais, científicas e técnicas).

Isso explica parte das discrepâncias, uma vez que há situações menos heterogêneas, seja em posições ocupacionais, seja em segmentos de atividade econômica, em que a participação dos dois grupos é praticamente igual e, ainda assim, a diferença persiste. Uma das respostas possíveis está no tipo de qualificação associada ao posto, inclusive do ponto de vista hierárquico. As informações a seguir apresentam essa abordagem da inserção dos negros, que ocorre, em grande parte, em ocupações semiqualificadas, associadas a níveis de escolaridade mais baixos do que a dos não negros e em larga desvantagem quanto aos postos em níveis hierárquicos mais altos. 


\section{OCUPADOS COM ENSINO SUPERIOR}

As análises de mercado de trabalho mostram que o crescimento do nível de atividade econômica com a criação de postos de trabalho é o principal fator de indução do decréscimo da taxa de desemprego e dos diferenciais apresentados nos indicadores por raça/cor.

No entanto, alcançar níveis de escolaridade mais altos, em qualquer contexto econômico, continua sendo um caminho importante na busca por um posto de trabalho de melhor qualidade e com maiores rendimentos, além de melhorar as chances nessa busca.

No que diz respeito à população negra, a disputa costuma ser mais árdua, pois tende a começar mais cedo e com desvantagens socioeconômicas históricas. Nesse sentido, as políticas públicas de acesso à educação, especialmente no Ensino Superior público, e as políticas de combate à discriminação racial foram importantes avanços na tentativa de redução das desigualdades entre negros e não negros. No âmbito do mercado de trabalho, algumas dessas desigualdades ainda persistem, sobretudo nos níveis mais altos de escolaridade.

Em 2018, o tempo médio de estudo dos ocupados com idade de 25 anos e mais era de 10,4 anos, mas os negros registraram uma média menor (9,5 anos) do que a dos não negros (11,0 anos) ${ }^{8}$. Essa diferença já foi maior e vem se reduzindo graças ao aumento do nível de escolaridade experimentado por toda a população nos últimos anos, principalmente pelos negros, cujo tempo médio de estudo aumentou 3,3 anos, entre 2000 e 2018 (os não negros tiveram aumento de 1,9 ano nesse período).

Do total de ocupados negros, em $2018,39,8 \%$ possuíam níveis de escolaridade abaixo do Ensino Médio completo (contra 25,1\% dos não negros), enquanto 49,0\% concluíram o Ensino Médio, proporção ligeiramente maior do que a dos não negros (48,4\%). Este foi um grande avanço, pois, se observados os percentuais de 2000 , por exemplo, $19,5 \%$ dos ocupados negros e $31,0 \%$ dos não negros possuíam Ensino Médio completo (Gráfico 6). Nesse ano, a obrigatoriedade relacionada aos estudos ainda não era estendida até o Ensino Médio, fato que coloca como pressuposto aumentos progressivos do nível de escolaridade devido à redução da evasão escolar.

8 As mulheres ocupadas com 25 anos de idade e mais estudam mais tempo que os homens, embora para os negros essa diferença, em 2018, fosse um pouco menor ( 9,9 anos mulheres e 9,2 anos homens) do que entre os não negros (11,4 anos e 10,7 anos, respectivamente). 
O afunilamento no Ensino Superior ocorre sobretudo entre os negros (11,2\% dos ocupados negros completaram esse nível de ensino e $26,6 \%$ dos não negros). Dificuldades financeiras e de conciliação entre estudo e trabalho, distância entre essas localidades e a residência, além de desestímulos de várias ordens podem ser mencionados para ajudar a entender esse desequilíbrio. De qualquer modo, é importante notar que entre 2000 e 2018 a proporção de ocupados negros que completaram o Ensino Superior mais que triplicou.

Gráfico 6 - Distribuição dos ocupados, por nível de escolaridade, segundo raça/cor. Região Metropolitana de São Paulo - 2000-2018
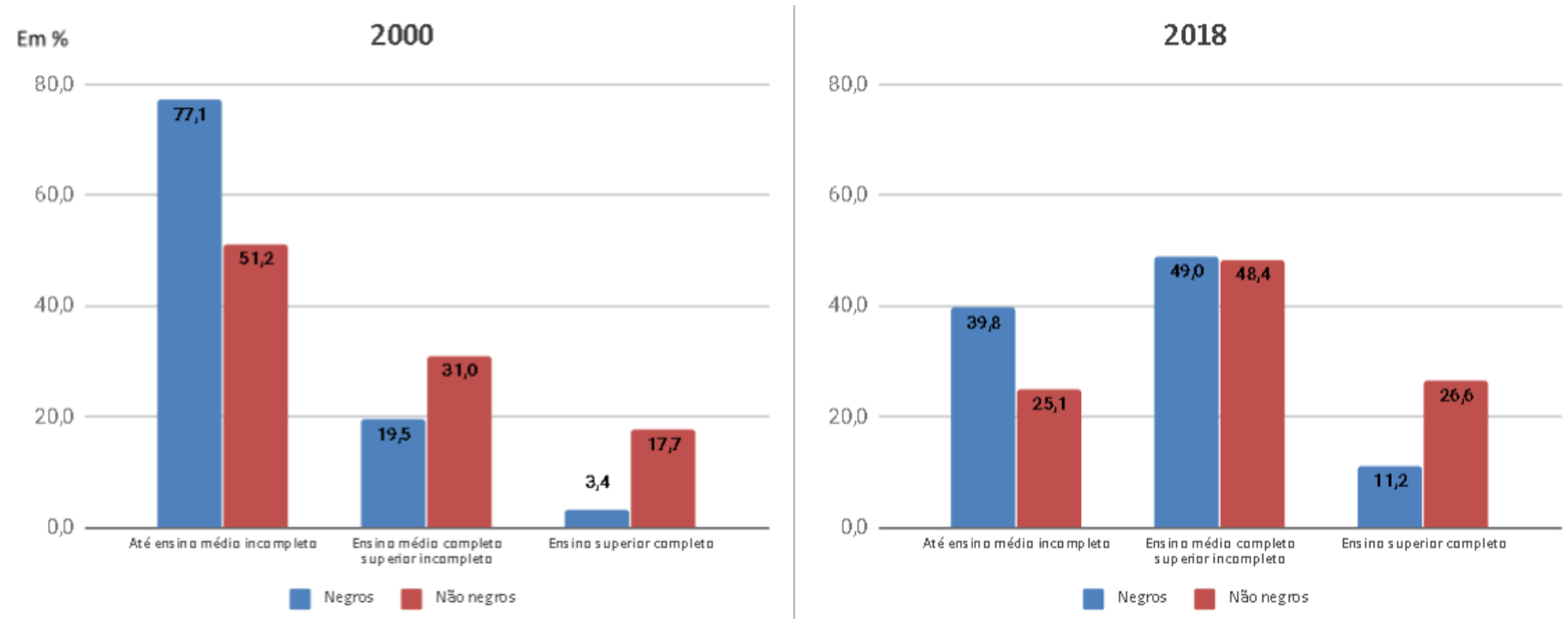

Fonte: Secretaria de Planejamento e Gestão. Convênio Seade-Dieese e Ministério do Trabalho/FAT. Pesquisa de Emprego e Desemprego (PED).

Considerando essas diferenças entre negros e não negros referentes ao tempo de estudo e ao nível de escolaridade, bem como à inserção ocupacional, buscou-se observar especificamente a parcela de ocupados que havia completado o Ensino Superior, para avaliar em que medida os diferenciais se apresentariam.

Obter níveis mais altos de escolaridade propicia melhores condições para se chegar a cargos mais qualificados e com rendimentos maiores do que aqueles com escolaridade mais baixa. Entretanto, os diferenciais de rendimentos são maiores entre negros e não negros com nível de Ensino Superior (Gráfico 7). Os ocupados negros que não completaram o Ensino Médio ganhavam 6\% menos do que os não negros com esse nível de ensino, e aqueles com Ensino Médio completo obtinham rendimentos $12 \%$ menores, enquanto os que possuíam Ensino Superior recebiam 37\% menos. 
Gráfico 7 - Rendimentos médios reais(1), por nível de escolaridade, segundo raça/ cor. Região Metropolitana de São Paulo - 2018

\section{Em reais}

5.000

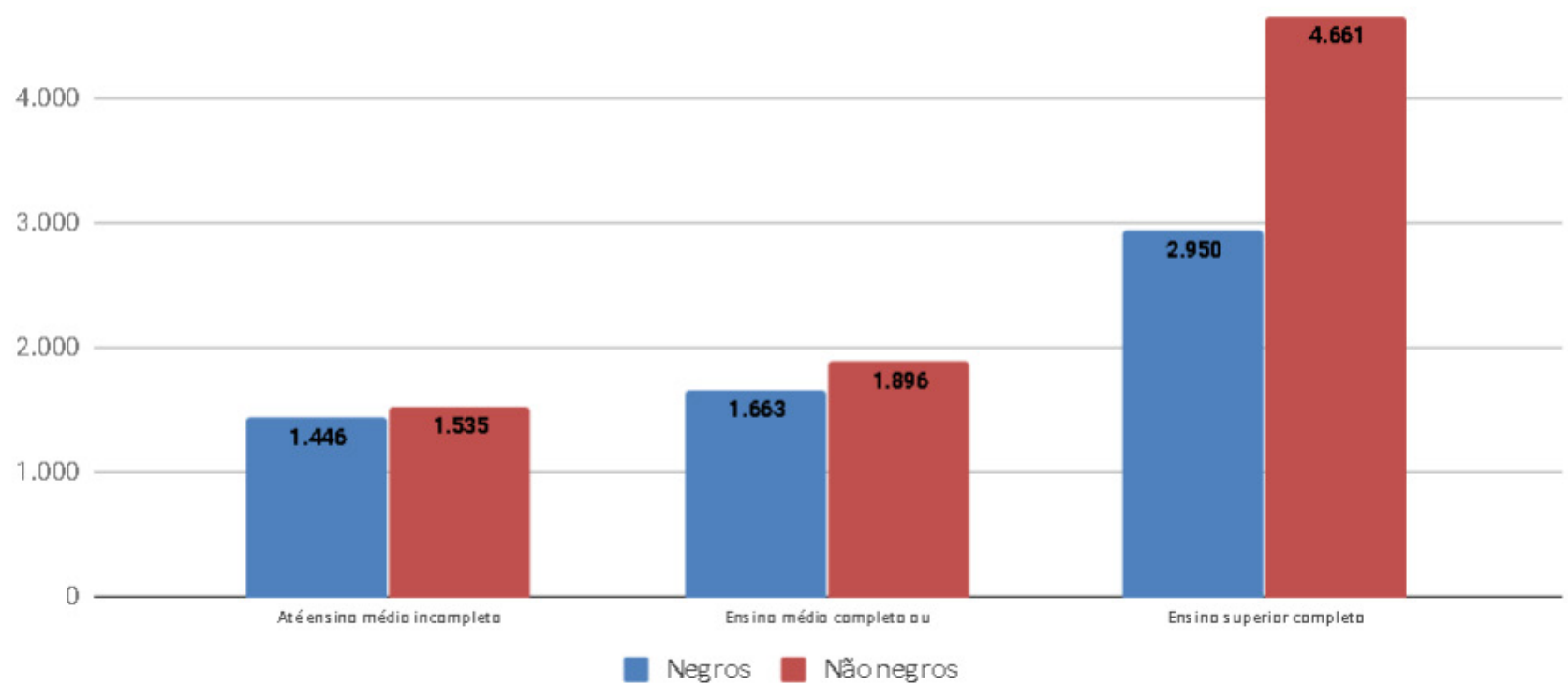

Fonte: Secretaria de Planejamento e Gestão. Convênio Seade-Dieese e Ministério do Trabalho/FAT. Pesquisa de Emprego e Desemprego (PED).

(1) Inflator utilizado: ICV do Dieese. Em reais de novembro de 2018.

A diferença mais acentuada entre aqueles que completaram o Ensino Superior pode ser melhor entendida ao se observar o tipo de posto preponderantemente ocupado por um e outro segmento de raça/cor. Em 2018, enquanto 33,4\% dos ocupados negros com Ensino Superior estavam no grupo de direção, gerência e planejamento ${ }^{9}$, os não negros nesse mesmo grupo eram 49,4\% (Gráfico 8). Já os negros nos grupos que desenvolviam tarefas de execução $(38,8 \%)$, em especial em postos semiqualificados ${ }^{10}$, e tarefas de apoio $(22,8 \%)$, estavam em maior proporção do que os não negros (29,7\% e 16,2\%, respectivamente).

9 No grupo direção, gerência e planejamento estão os ocupados com função de planejar, coordenar e supervisionar tarefas; no grupo tarefas de execução estão os ocupados diretamente ligados às atividades fim no segmento de atividade econômica na qual trabalham e podem ser classificados como qualificados (maior grau de especialização), semiqualificados (tarefas repetitivas com menor grau de complexidade) e não qualificados (em geral, trabalhos que demandam esforço físico); e o grupo tarefas de apoio é formado por profissionais que exercem tarefas complementares àquelas que caracterizam a principal atividade da empresa ou negócio em que atuam e podem ser divididos em três subgrupos: serviços não operacionais (tarefas administrativas, comercialização, manutenção, etc.), serviços de escritório (secretária, recepcionista, etc.) e serviços gerais (faxineiro, porteiro, segurança, etc.).

10 O destaque para os ocupados em postos semiqualificados no grupo de tarefas de execução foi feito com base em informações de anos anteriores, uma vez que, para esse estudo, os dados dos subgrupos não foram disponibilizados. 
Gráfico 8 - Distribuição dos ocupados com Ensino Superior completo, por grupos de ocupação, segundo raça/cor. Região Metropolitana de São Paulo - 2018

\section{Em \%}

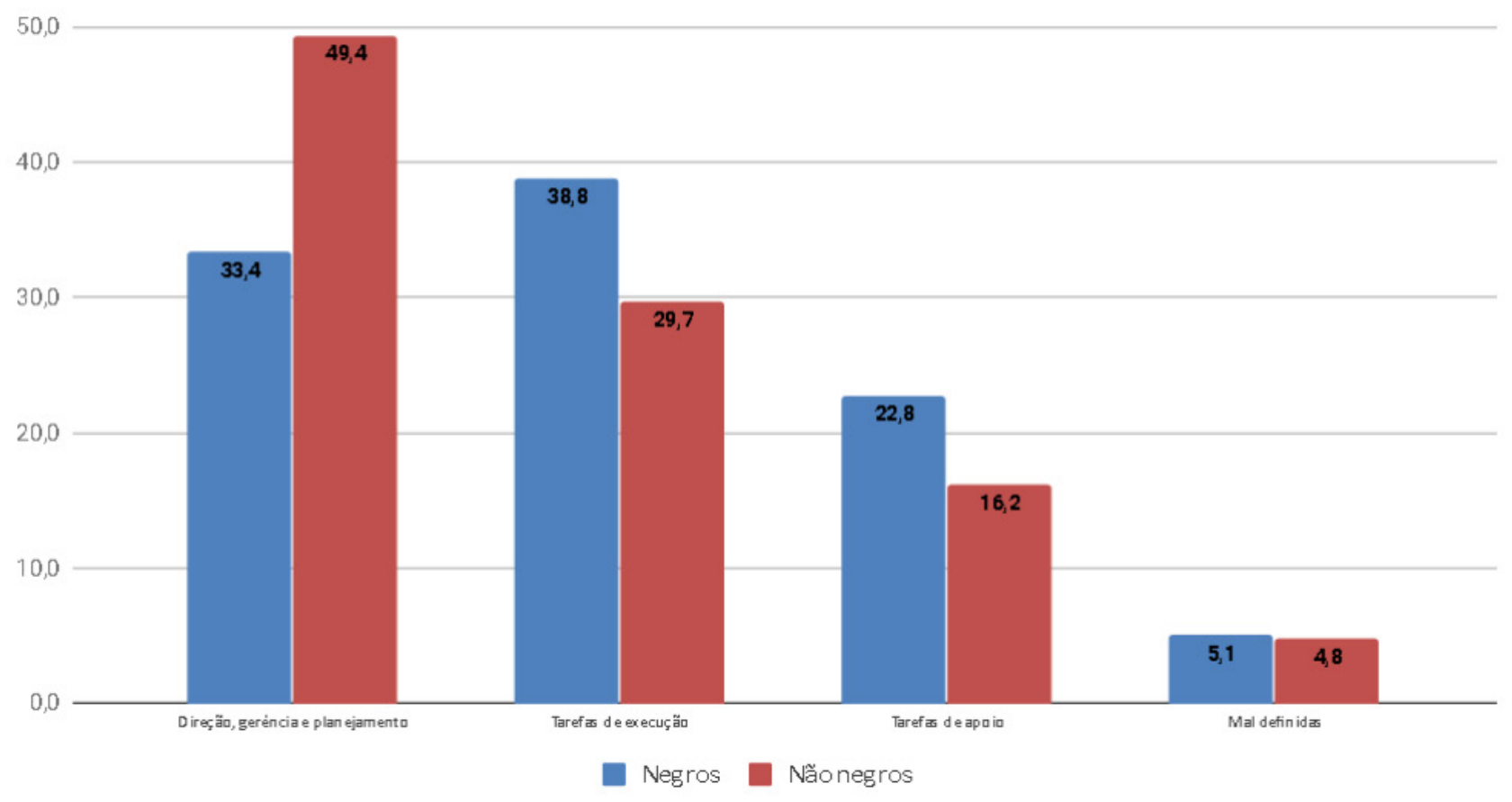

Fonte: Secretaria de Planejamento e Gestão. Convênio Seade-Dieese e Ministério do Trabalho/FAT. Pesquisa de Emprego e Desemprego (PED).

Essa distância é notada entre os rendimentos de quem ocupa cargos de direção, gerência e planejamento, 37\% menor para os negros, e diminui entre os rendimentos do grupo de tarefas de execução ( $22 \%$ menor) e de apoio (19\% menor, conforme Gráfico 9). 
Gráfico 9-Rendimentos médios reais(1) dos ocupados com Ensino Superior completo, por grupos de ocupação, segundo raça/cor.

Região Metropolitana de São Paulo - 2018

\section{Em reais}

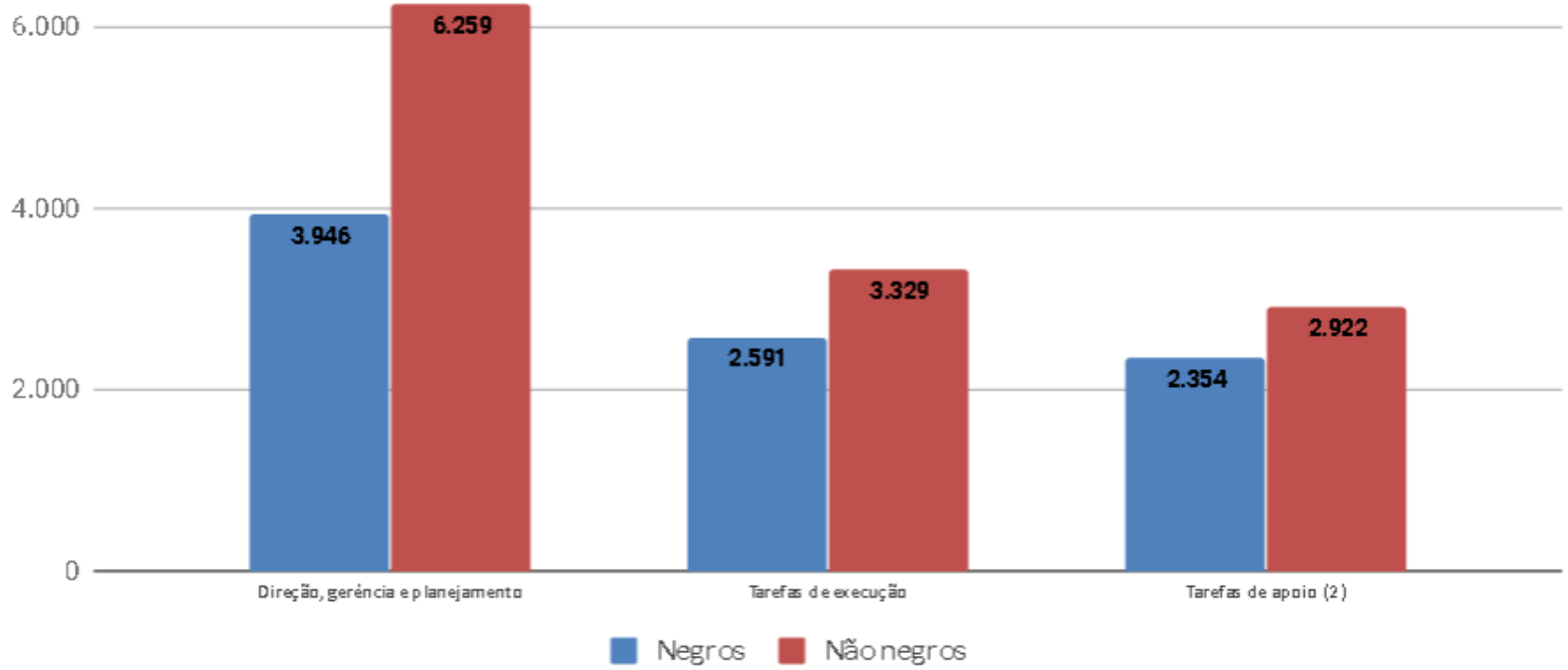

Fonte: Secretaria de Planejamento e Gestão. Convênio Seade-Dieese e Ministério do Trabalho/FAT. Pesquisa de Emprego e Desemprego (PED). Inflator utilizado: ICV do Dieese. Em reais de novembro de 2018. O valor atribuído aos negros apresenta erro amostral acima do usual. 


\section{CONSIDERAÇÕES FINAIS}

Essas informações mostram que, a despeito do aumento do tempo médio de estudos da população negra ocupada, ainda permanecem importantes diferenças em relação aos não negros, principalmente entre aqueles que completaram o Ensino Superior. Esse fato, associado à menor presença de negros com o mesmo nível de ensino em cargos de liderança (e maior proporção nos de tarefas de apoio), revela que as políticas públicas de acesso a todos os ciclos de ensino e a criminalização de manifestações de preconceito ou de racismo são medidas importantes diante das desigualdades racial e social, cujas raízes estão na formação da sociedade colonial brasileira. Essas políticas atuam na tentativa de superação das dificuldades históricas que foram impostas a essa população. Tais dificuldades envolvem, entre outras tantas, completar os estudos e obter níveis mais altos no ensino e na carreira profissional, fatores que impactam os rendimentos do trabalho e as condições de vida.

Em convergência com essas medidas, a formação e a valorização da identidade negra e de suas representações sociais, de certa forma previstas no Estatuto da Igualdade Racial, são condições fundamentais para a afirmação da raça/ cor e a autoafirmação do indivíduo, repercutindo positivamente nos demais segmentos da população, a ponto de contribuir para a redução de formas silenciosas de discriminação que, em um ambiente de trabalho, por exemplo, impedem ou dificultam a ascensão profissional dos negros.

Nas palavras dos representantes dos movimentos negros, a abolição ainda não se completou. Pode-se dizer, assim, que a sociedade também não, bem como a economia não progrediu da fase colonial para sua completa nacionalização e independência. Para que se completem, seria preciso alcançar a verdadeira democracia racial, social e política. Os estudiosos da nossa história e os dados estatísticos atuais mostram que o melhor instrumento para isso, mas não 0 único, é a garantia de acesso à educação e ao trabalho de melhor qualidade para a população em geral, mas com ações direcionadas à população negra. 


\section{Blacks and the differences in labor market in São Paulo metropolitan area: reflections on employees' level of education}

Abstract: Racial inequality has its origin in the plantation economy in the colonial era, and still can be seen in contemporary labor market. Data from Research on Employment and Unemployment (Pesquisa de Emprego e Desemprego - PED) show that unemployment rate among Blacks, reaching $19,2 \%$ in $\mathbf{2 0 1 8}$, is traditionally higher than non-Blacks'. Their occupational insertion takes place mostly in lower-qualified and lower-paid jobs than nonBlacks'. Despite a significant increase in education level, higher-educated Blacks employees correspond to less than half of their non-Black counterparts, and income differences by race/color of those with this level of education are the highest.

Keywords: Racial inequality. Labor market. Unemployment rate. Level of education. Employment. 


\section{Los negros y las diferencias en el mercado de trabajo de la región metropolitana de São Paulo: consideraciones sobre el nivel de escolaridad de los ocupados}

Resumen: La desigualdad racial tiene su origen en el funcionamiento de la economía de plantación del período colonial y aún puede ser percibida en el mercado de trabajo actual. En la región Metropolitana de São Paulo, las informaciones de la Pesquisa de Empleo y Desempleo (PED) muestran que la tasa de desempleo de los negros, de 19,2\% en 2018, es tradicionalmente más elevada que la de los no negros. Su inserción ocupacional suele ocurrir en plazas cuya calificación y los rendimientos son más bajos que aquellos de los no negros. A pesar del importante aumento del nivel de escolaridad, la proporción de ocupados negros con formación superior equivale a menos de la mitad de la participación de los no negros y los diferenciales por raza/color de los rendimientos de quien posee ese nivel de enseñanza son mayores.

Palabras clave: Desigualdad racial. Mercado de trabajo. Tasa de desempleo. Nivel de escolaridad. Ocupación. 


\section{REFERÊNCIAS}

CANDIDO, Antonio. The Brazilian family. In: SMITH, T. Lynn; MARCHANT, Alexander (org.). Brazil: portrait of half a continent. Nova York: The Dryden Press, 1951.

EMORY UNIVERSITY/UNIVERSITY OF HULL. Voyages: The Transatlantic Slave Trade Database. Atlanta, EUA: Emory University; Kingston upon Hull, Inglaterra: University of Hull. Disponível em: www.slavevoyages.org/assessment/ estimates. Acesso em: 21 nov. 2018.

FERNANDES, Florestan. A integração do negro na sociedade de classes. São Paulo: Biblioteca Azul, 2008.

FERNANDES, Florestan. Circuito fechado: quatro ensaios sobre o "poder institucional”. São Paulo: Editora Globo, 2010.

FERNANDES, Florestan; BASTIDE, Roger. Brancos e negros em São Paulo. São Paulo: Global Editora, 2010.

FERNANDES, Florestan. Significado do protesto negro. São Paulo: Expressão Popular e Fundação Perseu Abramo, 2017.

FUNDAÇÃO SEADE. Inserção da população negra no mercado de trabalho. São Paulo, 2008-2018. Disponível em: http://www.seade.gov.br/produtos/ ipnmt/?regiao=rmsp. Acesso em: 02/05/2019.

FUNDAÇÃO SEADE. PIB - Produto Interno Bruto, PIB Regional. São Paulo, 2019. Disponível em: http://www.seade.gov.br/produtos/pib-anual/. Acesso em: 26/06/2019.

FURTADO, Celso. Formação econômica do Brasil. São Paulo: Companhia das Letras, 2007.

IANNI, Otávio. Escravidão e racismo. São Paulo: Hucitec, 1988.

PRADO Júnior, Caio. Formação do Brasil contemporâneo. São Paulo: Companhia das Letras, 2011.

SELLIN, Alfred Wilhelm. Das Kaiserreich Brasilien. Leipzig: G. Freytag, 1885. p. 177. 


\section{SOBRE A AUTORA:}

Leila Luiza Gonzaga é pós-graduada em Economia e Gestão das Relações de Trabalho pela Pontifícia Universidade Católica de São Paulo (PUC-SP). Atua como analista de projetos na Fundação Sistema Estadual de Análise de Dados (Seade).

E-mail: leilagonzaga@seade.gov.br

Recebido em: dezembro de 2018

Aprovado em: abril de 2019 